\title{
Community based intervention to prevent domestic violence against women in the reproductive age in Northwestern Ethiopia: a protocol for quasi-experimental study
}

Agumasie Semahegn ${ }^{1,2^{*}}$, Kwasi Torpey ${ }^{1}$, Abubakar Manu$^{1}$, Nega Assefa ${ }^{2}$ and Augustine Ankomah ${ }^{1}$

\begin{abstract}
Background: Violence against women is a well understood devastating global pandemic, and human right violation. One in three women experienced intimate partner violence worldwide. In Ethiopia, the level of domestic violence against women is one of the highest in the world. However, Ethiopia is signatory for various conventions and incorporated in legal frameworks. Nevertheless, effective implementation of the existing policy documents, and engaging different stakeholders is very limited. Therefore, we aimed to pilot feasibility of implementing available research evidence and policy documents at community level to prevent domestic violence against women in Awi zone, northwestern Ethiopia.

Methods: A community-based quasi-experimental study design will be employed using mixed method. Multistage stratified systematic sampling and purposive sampling will be used to recruit quantitative and qualitative study participants, respectively. A total of 1,269 women will be participated in the intervention, active comparator and control groups. Pre and post-test quantitative data will be collected using face-to-face interview. Qualitative data will be collected through indepth, key informant interview and focus group discussions. Intervention: advocacy meeting will be held to persuade local politicians and sustain the implementation of community based intervention to prevent domestic violence against women. Community representatives will be trained to enhance peer education to promote community awareness and engage stakeholders to transform the traditional gender norm within local context. Awareness creation and husband involvement will be made through integrating the intervention with community health extension program. Only husband involvement will not be promoted in the active comparator to test the role of husband involvement on the domestic violence prevention activities. Intervention progress will be monitored regularly. Gathered data will be entered in Epidata and exported to SPSS (23.0) software for analysis. Descriptive statistics, logistic regressions, intention to treat analysis and difference in differences will be computed. Qualitative data will be transcribed, color coded, thematically analyzed and arranged using Nvivo.
\end{abstract}

Discussion: This interventional study is aimed to design, pilot and translate proven research evidence, agreed conventions and country policy document to real setting implementation. We are expecting to initiate implementation of culturally acceptable intervention through engaging stakeholders. Policy makers, planners and any concerned bodies will be benefited.

Trial registration: ClinicalTrials.gov ID: NCT03265626

Keywords: Domestic violence, Women, Intervention implementation, Community, Ethiopia

\footnotetext{
* Correspondence: agucell@yahoo.com

'Department of Population, Family and Reproductive Health, School of

Public Health, College of Health Science, University of Ghana, Legon, Accra,

Ghana

${ }^{2}$ College of Health and Medical Sciences, Haramaya University, Po. Box 235,

Harar, Ethiopia
} 


\section{Plain English summary}

Violence against women is a well-recognized reproductive health issue. It is a cross-cutting issue which is interlinked with every day's routine activity and overall development agenda in the world. Several primary studies have been conducted on the area that briefly report the level and associated factors of the domestic violence against women. Moreover, some interventional studies also conducted in different parts of the world revealed that interventions mainly focused on gender norm, societal culture and other behavioral change communication can improve the prevention strategies to tackle domestic violence against women. Nevertheless, many countries still have a limited motivation to implement their policy in real setting to prevent violence against women. One of the most dilemmatic issue is considering violence against women as a private matter, and still there is lack of clear understanding on the difference of private and public matters. Therefore, this study aims to mobilize community to prevent domestic violence against women. It will contribute evidence to program planners, policy makers, clinicians and other stakeholders to have informed decision on the issue of domestic violence against women.

\section{Background}

Gender based violence against women is a well-recognized public health problem, gross pervasive abuse of human rights, and major obstacle for achieving the sustainable development goals worldwide [1-6]. Globally, one in three women experience violence against women (VAW) $[4,7$, 8]. About $38-60 \%$ of murders of women are committed by intimate partners every year. Domestic VAW is not only an exhibit of unbalance of power, and a bad women's life experience at their home $[9,10]$, it accounts for $5 \%$ loss of women's healthy years. The morbidity and mortality due to VAW is more than a cumulative burden of cancer, road traffic accidents and malaria, a huge threat and unmanageable global burden to public health for the future [10]. According to World Health Organization (WHO) multicounty study indicated that intimate partner violence in Ethiopia was $71 \%$, which is the highest in the world [11]. Research evidence show that domestic violence is strongly linked with gender inequality that affect women's ability to have a discussion on several reproductive health issues including human immunodeficiency virus (HIV) and negotiate on condom use [12-14]. The cost of VAW is estimated from $1.2-3.7 \%$ of the country's gross domestic product, which is equivalent to what many governments spend on primary education [8]. Nevertheless, most governments have considered domestic VAW as minor social tricky, private matter and not taken as crime $[1,10,12]$.

The United Nations aims to create an enabling household environment, improve women's right, political, economic empowerment and legal protection [15]. Consistently, the
Maputo Plan of Action (2016-2030) gives due attention to the implementation of international, regional and national legislations to tackle VAW [16]. On the other hand, a systematic review suggested that women empowerment and community mobilization averted $\$ 13-19$ per disability adjusted life year. Hence, gender responsive interventions that target traditional gender norms, behavior change communication and structural drivers are cost effective approaches to prevent VAW [17]. Likewise, domestic VAW is strongly associated with gender norms, poverty, denied access to education, embedded in social customs, lack of autonomy, inequitable gender attitudes, women accept justified wife beating and alcohol use [1, 2, 5, 18-23].

Moreover, domestic VAW is significantly associated with various poor health outcomes (low birth weight, premature birth, malnutrition, suicide, homicide, mental illness, physical injuries, disability and non-communicable diseases) [1, $6,7,18,20,24-29]$. In addition, VAW has been associated with HIV and other sexual transmitted infections (STIs) acquisition, unintended pregnancy, induced abortion and other poor reproductive health conditions $[1,5,7,10,14$, 19-21, 23, 27, 30-43]. It is a cross cutting issue which requires comprehensive approach to address it (microfinance support, equality norm or culture transformative training; communication skill in relationship; minimize access to alcohol use and community health education [1, $20,44]$. The conceptual framework that shows the detail of factors associated with domestic VAW included as an additional file (Fig. 1).

In Ethiopia, domestic VAW is a common women's life experience. A systematic review on studies done in Ethiopia (2000-2014) indicated that any intimate partner violence (IPV) is a known phenomenon in the country which ranged from 20 to $78 \%$ [45]. In response to this, the government of Ethiopia has incorporated the issue of women's right and gender equality in the constitution (Article 35 and 89(7)) [46], criminal code under proclamation NO.414/2004 (Article 564) [47] and Family Code Proclamation No. 213/2000 [48]. Violence against a marriage partner or a person cohabiting in an irregular union is prohibited. In addition, access to and control over resource including other rights and responsibilities of partners in marriage or cohabitation are clearly addressed in the policy documents. Moreover, Ethiopian Ministry of Health has developed a standard operating procedure for the response and prevention of sexual violence in Ethiopia in 2016 [49]. Community mobilization, stakeholder engagement and partner involvement are the most prioritized intervention programs which need effective implementation, but these are still very limited. Furthermore, this implementation research will give an insight to mobilize resource, involve stakeholders to put the existing law and regulations into action and identify implementation bottlenecks. Given the paucity of evidence, it will provide 


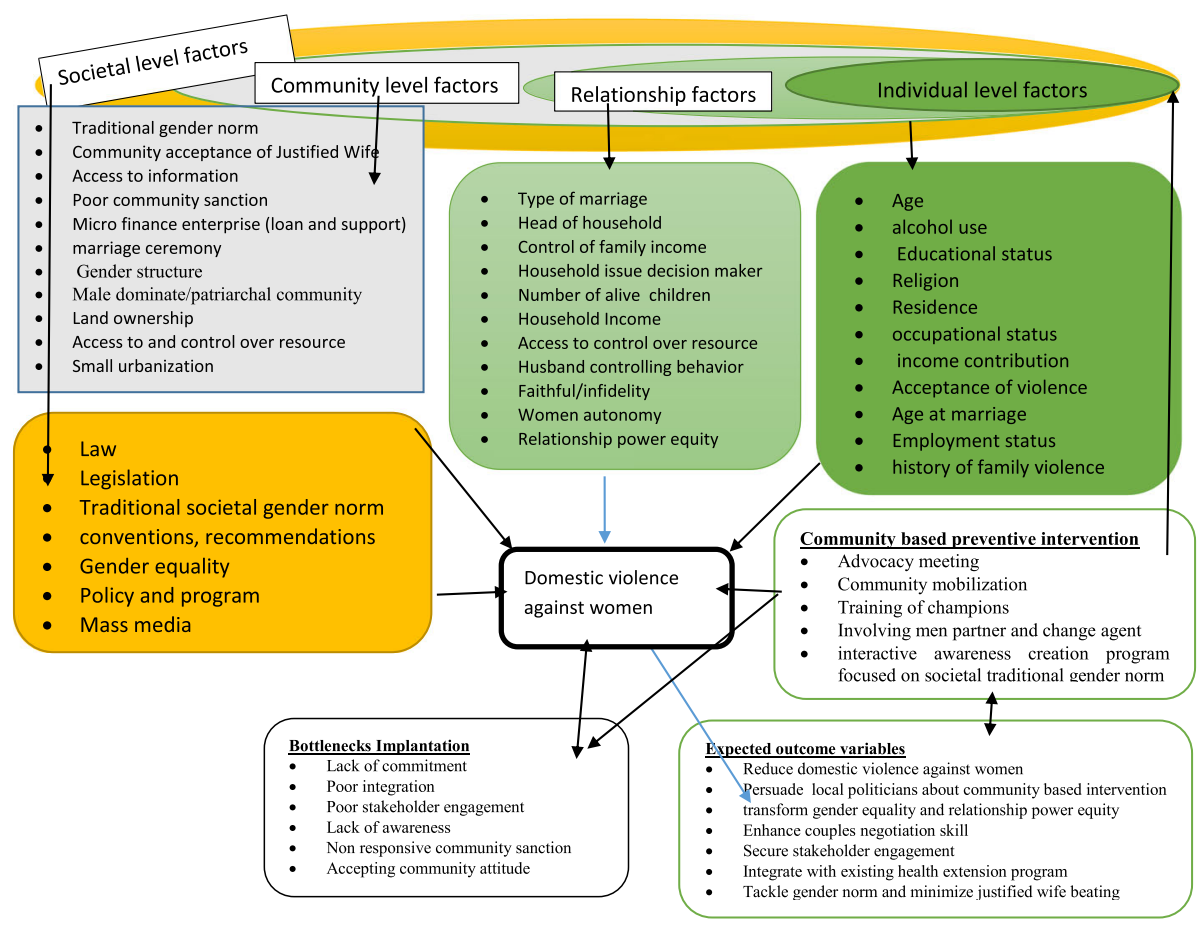

Fig. 1 Conceptual framework adapted from ecological model

information on feasibility and implementation of community based preventive intervention programs.

\section{Study objective}

The overall aim of this study is to assess the outcome of community based intervention to prevent domestic violence against married or cohabiting women in the reproductive age and associated factors in Awi zone of the Northwestern Ethiopia from November 15, 2017 to November 15, 2018.

\section{Specific objectives}

1. To assess the baseline level of domestic VAW in the study area

2. To identify associated factors of domestic VAW in the study area

3. To explore implementation bottlenecks in VAW program in the study area

4. To implement culturally acceptable interventions to address domestic VAW

5. To assess the outcome of community based intervention on domestic VAW

\section{Methods}

\section{Study setting}

This study will be conducted in Awi zone, Amhara regional state, Northwestern Ethiopia. Enjibara town is the administration center of Awi zone which is located
$447 \mathrm{~km}$ from Addis Ababa. Based on the 2007 Census, it has a total population of 982,942 and 491,077 of them are women. Only $12.5 \%$ of population are based in urban. Based on the preliminary assessment; Awi zone administration has nine districts with a total of 204 subdistricts and 6463 development armies. Sub-district is the smallest administrative unit which has an estimated 1000-1500 households or 5000 total population. In one of the district of the Awi zone, Faggetalekoma district has one of the highest record in domestic VAW $[45,50]$. The women and children affair office has structured by the government to execute such type of issues. The zonal health department and district health offices have been implementing the standard operating procedures to respond and prevent sexual violence.

\section{Study design and participants selection}

Community based three arm quasi-experimental design will be employed usingquantitative and qualitative techniques (mixed methods).

\section{Quantitative study participants}

Married or cohabiting women (15-49 years) will be recruited for the quantitative study. Study participants will be allocated into intervention, active comparator and control groups. Three districts will be selected out of nine districts considering stability or mobility status, convenience to implement intervention and monitor the 
control. The study design and participant allocation is illustrated as an additional file (see Fig. 2).

\section{Qualitative study participants}

Community representatives (local leaders, religious leaders and elders), husbands, health care providers, police and women affair office representatives will be involved.

\section{Inclusion criteria}

- Women (15-49 years) from the general population

- Married/cohabited women who have stayed at least 12 months with the current husband

- Women and community representatives who have registered or recognized as permanent resident at least for 6 months

\section{Exclusion criteria}

- Women and or community representatives who will unable to respond due to severe physical or mental illness

\section{Sample size determination}

The sample size is determined considering both the intervention and control using a formula recommended for dichotomous outcome variable. We assumed that implementation of community based intervention program to prevent domestic VAW is superior as compared with the standard service [51]. In addition, we considered 5\% margin of error, 95\% significance level and $80 \%$ power.

$$
N=2 \times\left(\frac{z_{1-\alpha}+z_{1-\beta}}{\mathrm{d}-\delta_{0}}\right)^{2} \times p \times(1-p)
$$

Where as; $\mathrm{N}$ is the sample size of each group, $\mathrm{P}$ is prevalence in standard intervention (control arm), d: the real difference between two treatment effects $\left(\mathrm{d}=\mathrm{P}_{\mathrm{o}}-\mathrm{P}_{\mathrm{x}}\right) ; 22 \%-9 \%$ $=13 \%=0.13$ : study done in Uganda $(22 \%)$ in the standard intervention group [52]; $\delta_{0:}$ statistical acceptable margin (5\%); a: significance level at $95 \%(a=1-0.95=0.05=1.645)$, ß. $80 \%$ power $(B=1-0.8=0.2=0.845$. Then, $15 \%$ is added for potential non-achievements. Furthermore, due to the multistage sampling, design effect is considered to boost the power and precision that taken from the design effect of women experienced physical or sexual violence in the study area (Amhara region) in the last 12 months was 1.11 [53]. Eventually, a total 1269 women is obtained for the three arms (i.e. 423 for each group). The number of qualitative study participants will be determined by information saturation. However, a minimum 12 in-depth interviews and two focus group discussions (FGDs) (male versus female groups) which comprise 8-10 discussants will be conducted.

\section{Sampling procedure}

Multistage, stratified and systematic sampling will be used to recruit study participants at their permanent place of residence. Three districts are selected out of nine districts in Awi zone (comprehensive intervention, active comparison and control). Then, six sub-districts (two sub-districts from each district) will be selected purposefully considering appropriateness for intervention, resource, and geographical non-proximity to control information contamination between intervention and controls. Then, sub-districts will be stratified (urban versus rural) to control the awareness level,

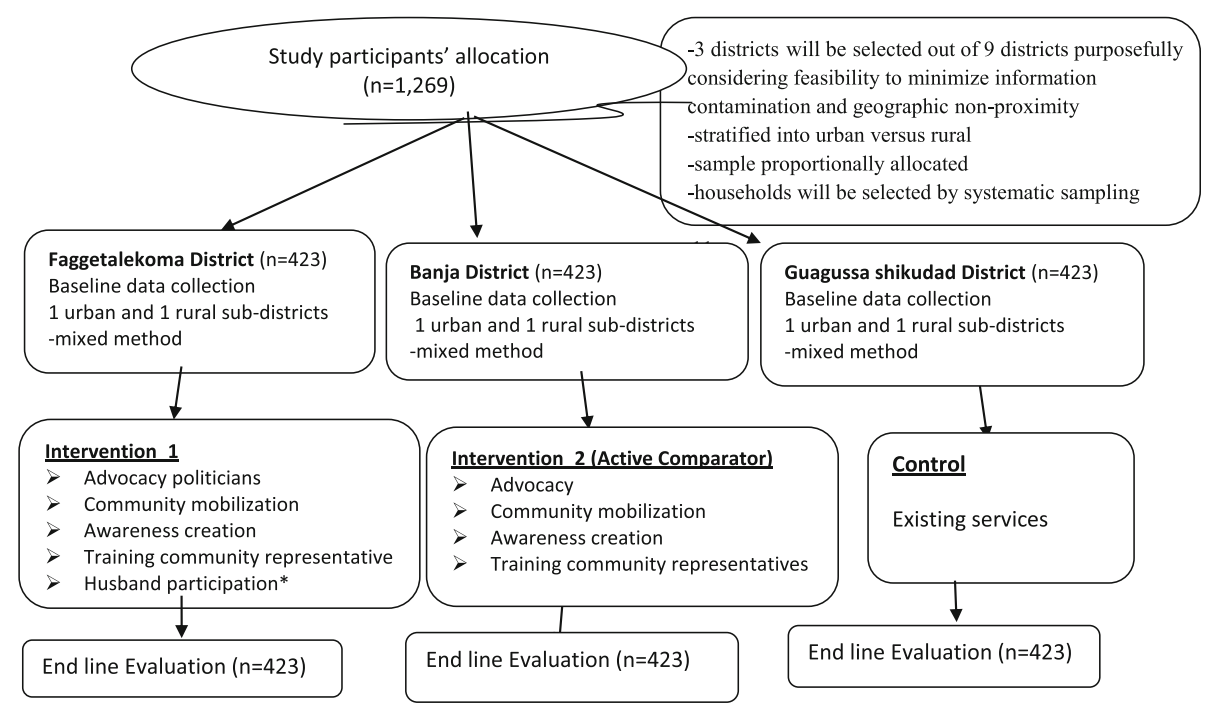

Fig. 2 Illustration of quasi-experimental design for intervention implementation 
access to information and community traditional gender norm variability between urban and rural dwellers. After that, the sample of the group will be proportionally allocated to size of each selected sub-district. The number of eligible households for this study will be identified using the community based health extension workers registry. Eventually, systematic sampling will be employed to select actual study participants at household level. Unique code will be given to selected households for intervention monitoring and finally endline evaluation purpose. In the meantime, if two married women are present in one household, only one woman will be selected using lottery method for interview.

Purposive sampling method will be used to select study participants for in-depth interview, key informant interview (KII) and FGDs. Community leaders will be consulted and actively involved on the recruitment of the most knowledgeable community representatives for in-depth interview, KII and FGDs. It will be conducted to explore individual and community perception about domestic VAW, sex negotiation, decision making, community gender norm, wife beating attitudes and community responses.

\section{Measurement tools}

Data will be collected using structured and semi-structured questionnaire that is adapted from various literature [29, $41,50,54-70]$. The tool will be pretested and modified to suit with the local context. It will consist of demographic, socio-economic variables about the women, relationship, community and societal level factors of domestic violence. In addition, the tool will comprise questions about the experience of psychological, physical and sexual violence. Moreover, semi-structured interview guide will be designed for qualitative study to explore the underlying bottlenecks in the community that hinder intervention implementation.

\section{Data collection procedure}

Data will be collected using sequential explanatory mixed method (quantitative 1 and 2, and qualitative 1 and 2) for baseline, monitoring and endline assessment. It is illustrated and attached as additional file (see Fig. 3) that is adapted from other study [71]. Face-to-face interview will be used for quantitative data collection. In-depth interview, KII and FGDs will be carried-out for qualitative study. The KII will be conducted on community representatives, district council members, women affair office, police officers, lawyers, health care providers and nongovernmental organization. Gender specific FGDs will be held on men and women to assess societal perception about domestic VAW. All participants' socio-demographic data will be captured using anonymously coded structured questionnaire. Voice recorder, note taking and non-verbal communication during the discussion will be recorded as much as possible. An estimate of 60 to $90 \mathrm{~min}$ will be taken to conduct one FGD. Eventually, endline evaluation will be carried-out using the same structured questionnaire, data collectors and supervisors as of the formative assessment. Twelve female nurses, midwives or public health officers will be recruited to collect the data.

\section{Data quality assurance activities}

- Participants Allocation: Intervention and control group participants will be allocated based on their geographic non-proximity to minimize information contamination. In addition, regular monitoring will be carried out on both intervention and control groups.

- Data Collector's Recruitment and Training: Data collectors will be recruited through consulting local leaders to get appropriate data collectors. Then, female nurses, midwives and or public health officers who have diploma or above qualification will be recruited as data collector (research assistant) to enhance quality of the data to be collected. Two supervisor who have Master of Public Health and had previous field experience will be recruited. Three days training will be given for research assistants by the principal investigator which will

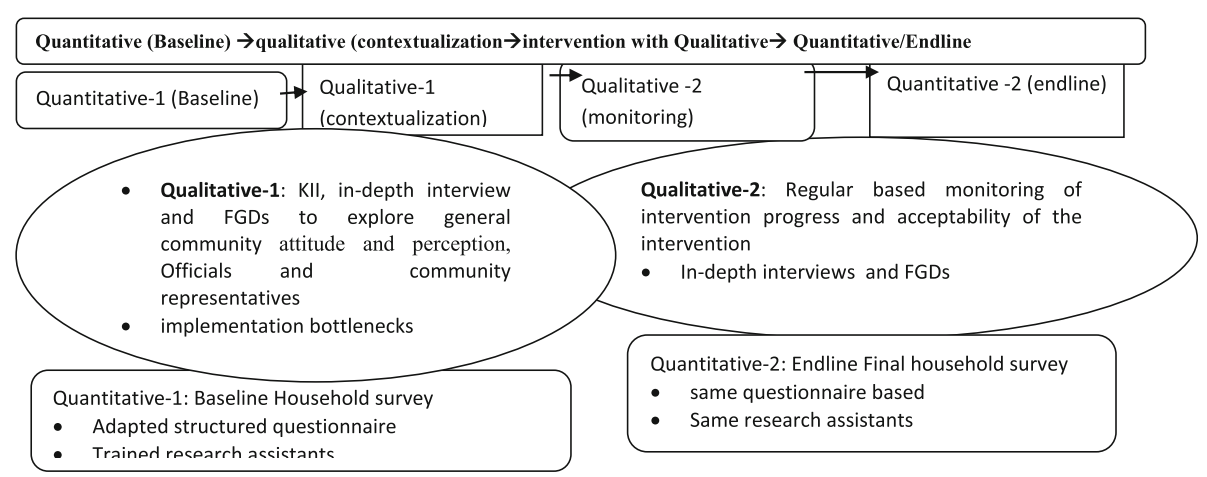

Fig. 3 diagrammatic show of the sequential explanatory mixed-method data collection process 
mainly focus on study objectives, sampling methods, data collection tool and procedures, interview techniques and ethics. Biomedical research ethical principles and $\mathrm{WHO}$ gender based violence research ethical guideline will be explained to research assistants. Regular supportive supervision will be given by principal investigator and supervisors.

- Implementers Recruitment and Training: Four community health extension workers as implementer and one supervisor will be recruited and deployed during the entire intervention period. Health extension workers who have been working in the sub-district will recruited as intervention implementer to ease integration with the existing innovative community based health extension program and working very closely with the community. Health Extension Workers (HEWs) will be re-oriented on the objectives, domestic VAW, gender inequality norm and how to integrate with their health extension package. Regular discussion and close supportive supervision will be given by principal investigator and facilitators.

- Pretest questionnaire: Pretest will be done on 5\% of the sample size from nearby district to test sensitive words in the questionnaire, sequence of questions, sampling, data collection procedure, consent taking, interview skill and note taking. Necessary amendment will be made accordingly.

- Tool Development and Validation: Intervention materials will be adapted from WHO and United Nation Population Fund (UNFPA) materials, research evidence, human right protection instrument and national policy documents. Most of domestic VAW research findings recommend addressing of wife beating accepting attitude, gender norm, gender equality, women empowerment, male involvement and legal sanctions. The adapted intervention materials for community mobilization, awareness creation and training of community representatives will be peer reviewed for validation. The research team will review it and necessary modification will be made accordingly. In addition, any feedback about the material will be received from advocacy meeting participants to contextualize with the community setting.

\section{Data processing and statistical analysis}

Both baseline and endline data will be checked and edited for completeness and consistency at field as well as at office. Explanatory and outcome variables will be clearly predefined prior to data entry, in which domestic VAW will be coded as if a woman reports at least one type of experience of either physical, psychological or sexual violence coded as "Yes $=1$ " and "No $=0$ ". Similar coding will be done for physical, sexual and psychological domestic violence against women to carry out subgroup analysis. On the other hand, women's wife beating accepting attitude will be measured using six questions or measurements, and also if women respond at least one justifying wife beating $[58,59,61]$. Similarly women autonomy will be measured in four indicators such as economic decision-making, reproductive health service utilization decision-making, extent of freedom of movement, and women's attitudes toward violence [54].

Then, data will be entered in Epidata (3.5.1) and exported to SPSS (23.0) for further cleaning and analysis. Multiple imputation will be done to handle missing data as necessary. Descriptive statistics, binary and multiple logistic regressions and Intention to Treat Analysis (ITTA) will be computed. Moreover, Difference in Differences (DID) will be calculated to determine the net intervention effect. Finally, statistical significance of intervention effect will be measured using adjusted prevalence ratio, adjusted odds ratio/risk ratio at $95 \%$ confidence interval (CI) and P-Value less than 0.05 . On the other hand, qualitative data will be transcribed through playing and replaying the voice recorder and also narrating the note taken during interviews or FGDs. The voice recorder audio will be listen as much as possible in quiet place. It will be transcribed independently by research assistant and principal investigator according to the verbatim of participants'. Then transcribed qualitative data will be translated from local language (Amharic) to English. The quotes will be narrated and cited using participant's code. Thematic areas will be identified and arranged based on their themes. Ideas will be color coded, and then merged accordingly. Qualitative data will be analyzed or arranged using Nvivo software.

\section{Implementation Design of the Community Based Intervention}

Evidence from clustered randomized controlled trials, community based quasi-experimental trials, longitudinal studies and systematic review on domestic VAW have been used to design intervention. In addition, recommendation of various community based research evidence, WHO recommendations, existing legal sanctions or policy documents (constitution, civil code, family laws and standard operation procedure to respond and prevent domestic VAW) will be used to implement the intervention. Intervention will be implemented using culturally appropriate and integrating with existing innovative community based health extension program. Interventions will be more focused on traditional gender norm, negotiation skills and involve men on domestic violence prevention activities. The intervention implementation will have contextualization, tool development and validation, advocacy, stakeholders' engagement and overall community mobilization activities. 


\section{Advocacy meeting and stakeholders engagement}

Advocacy meeting will be held to enhance awareness about domestic VAW problem, socioeconomic consequences, political implications, evidence based prevention strategies and country legal sanctions towards VAW. The advocacy meeting will be held every three months regularly for a year. It will create an entry point into the community and also involve stakeholders. Both the zonal and district health offices, women and child affair offices, police and security, office of justice, agriculture and land management office, women lawyer associations, nongovernmental organizations, community representatives (religious fathers, local leaders and elders) will be considered as potential stakeholders. However, stakeholder analysis will be made in Awi zone perspective to identify key stakeholders. Then, identified key stakeholders will be expected to be actively involved on the implementation process as per their hierarchy. Gender expert from health office and women and children affair office will be actively involved in the intervention implementation process.

The intervention will be implemented to address the risk factors according to Ecological Model (individual, relationship, community and societal level factors). Furthermore, piloting implementation intervention will focus on the five domain of implementation research domains (intervention, inner, outer, individual behavior and process settings) which clearly illustrated on Consolidated Framework for Implementation Research (CFIR) model, and presented in detail as additional file (see Fig. 4).

Arm 1: Comprehensive intervention group: comprehensive intervention to prevent domestic VAW and enhance existing policies will be conducted. The intervention will be focused on physical, psychological and sexual violence, decision making, negotiation, communication on household matters, gender equality and equity norms, and their relationship with women's health. Gender based training will be addressed about transformative gender norm. Comprehensive intervention will be comprised of the advocacy meeting, community mobilization activities, husband involvement and other awareness creation activities.

- Advocacy meeting/workshop: will be made to convince local people who are in position (authority) (police, women association, women affair office, health professionals) that have direct contribution to tackle VAW. Research evidence that show the magnitude, associated factors and proven solutions will be presented by the principal investigator. Thorough discussions will be made on the issue of VAW as per the local setting. It will allow to convince as well as dig out implementation bottlenecks. Leaflets, posters and any other awareness creation materials will be distributed to improve community attitude about VAW.

- Community mobilization: will be done at different public places (church and other social gathering events) about harmfulness of VAW, gender equality and equity, women autonomy on reproductive health, decision making on household issues and negotiation/communication skill. In addition, awareness creation activities will be carried out as

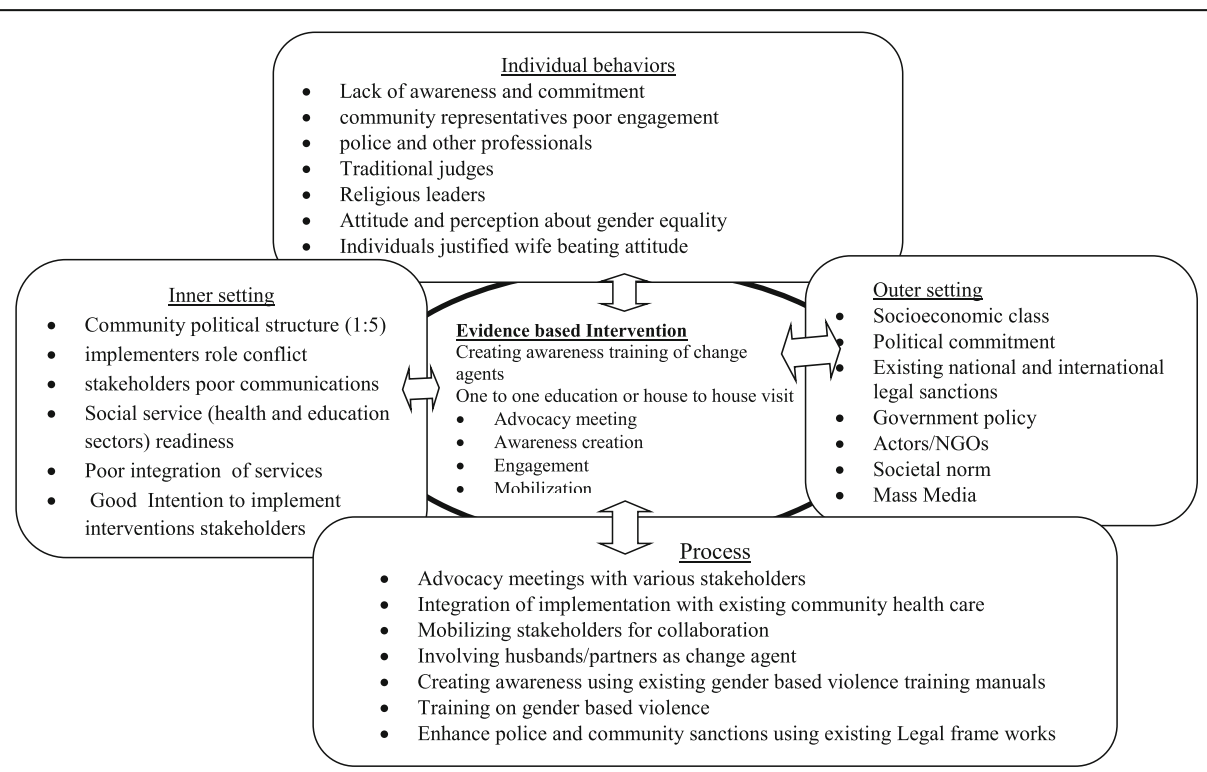

Fig. 4 Schematic presentation of Interacting domains using CFIR 
community conversation to reach the entire community within the study sites.

- Training: will be provided to community representatives as a change agent (leaders, religious fathers, elders, health care provider, police, local politicians and associations). Community believes, culture and religion are the main factors that affect attitude and gender norms. The training aims to improve awareness of public figures towards gender norm specifically on VAW. On each session of the training, discussion will be entertained to have common understanding of issues and discuss possible solutions.

All trainees are expected to disseminate information while going back to their home or religious place, community gathering areas (Idir, Equib, etc.) and also Sunday coffee ceremonies. Regular trainings to community representatives will be given every three months for a year in each intervention group.

- Awareness creation information dissemination: well oriented health extension workers will implement the awareness creation activities through house-to-house by integrating with the health extension package. The awareness creation will be more focused on gender equality, equity, decision making autonomy, negotiations skill in relationship and etc. this intervention will be given mainly to the women.

- Husband or partner involvement on domestic violence prevention: group health education and discussions will be held with husband or partners. Gender equality, equity, decision making, communication and involving on reproductive health issues as part of human right are the main issues that will be mentioned in this target group. Women's contribution in development and their right involving on household issues decision making will be raised and discussed.

ARM 2: Active comparator group: are all interventions listed above under comprehensive intervention (advocacy, community mobilization, awareness creation and training community representatives) will be provided to this group except active husband involvement intervention. The ultimate objective is to test the contribution of husband involvement on domestic VAW prevention.

Arm 3: Standard services (control group): the standard service will be sustained. We will regularly monitor to know what is going on in addition to the standard service during the study period for documentation purpose only.

\section{Expected outcomes}

\begin{tabular}{|c|c|}
\hline \multicolumn{2}{|c|}{ Expected Outcomes of the Community Based Intervention } \\
\hline \multirow[t]{2}{*}{ Specific objective 1} & $\begin{array}{l}\text { Conduct baseline assessment of domestic } \\
\text { VAW in the study area }\end{array}$ \\
\hline & $\begin{array}{l}\text { - determine the prevalence of domestic } \\
\text { VAW (physical, sexual, psychological) }\end{array}$ \\
\hline \multirow[t]{2}{*}{ Specific objective 2} & Identify associated factors of domestic VAW \\
\hline & $\begin{array}{l}\text { - Identify the associated factors } \\
\text { - explore community perception } \\
\text { - Explore stakeholders engagement level } \\
\text { - explore implementation barriers or } \\
\text { bottlenecks of VAW program } \\
\text { at implementers side }\end{array}$ \\
\hline \multirow[t]{2}{*}{ Specific objective 3} & $\begin{array}{l}\text { Design intervention implementation } \\
\text { strategy to tackle domestic VAW }\end{array}$ \\
\hline & $\begin{array}{l}\text { - Prepare the intervention material and } \\
\text { validate according to the local culture } \\
\text { - Integrate with community based } \\
\text { health extension program } \\
\text { - Conduct advocacy workshop and } \\
\text { work with the local administrative bodies }\end{array}$ \\
\hline \multirow[t]{9}{*}{ Specific objective 4} & $\begin{array}{l}\text { Implement culturally acceptable interventions } \\
\text { to address bottlenecks and DVAW }\end{array}$ \\
\hline & $\begin{array}{l}\text { *advocacy workshop four times a year } \\
\text { (4 session) }\end{array}$ \\
\hline & $\begin{array}{l}\text { - create awareness on politicians } \\
\text { - create champions of domestic VAW prevention } \\
\text { - enhance commitment to implement policy } \\
\text { documents at community level }\end{array}$ \\
\hline & $\begin{array}{l}{ }^{*} \text { community mobilization monthly for a } \\
\text { year ( } 12 \text { sessions) }\end{array}$ \\
\hline & $\begin{array}{l}\text { - involving the community in the domestic } \\
\text { VAW prevention } \\
\text { - engaging stakeholders } \\
\text { - create community ownership }\end{array}$ \\
\hline & $\begin{array}{l}{ }^{*} \text { Awareness creation to the women } \\
\text { (at least once per month) }\end{array}$ \\
\hline & $\begin{array}{l}\text { - enhance their communication and } \\
\text { negotiation skill } \\
\text { - enhance their awareness about gender } \\
\text { equality } \\
\text { - transform their wife-beating acceptance } \\
\text { attitude }\end{array}$ \\
\hline & ${ }^{*}$ involving husbands (6 to 12 sessions) \\
\hline & $\begin{array}{l}\text { - participate husbands/partner as change } \\
\text { agent } \\
\text { - enhance their awareness about gender equality } \\
\text { - improve masculine attitude } \\
\text { and transform }\end{array}$ \\
\hline \multirow[t]{2}{*}{$\begin{array}{l}\text { Specific } \\
\text { objective } 5\end{array}$} & $\begin{array}{l}\text { To assess the outcome of community } \\
\text { based intervention on domestic VAW }\end{array}$ \\
\hline & $\begin{array}{l}\text { - conduct endline assessment } \\
\text { - perform data analysis to determine the } \\
\text { prevalence of domestic VAW } \\
\text { - compute the difference between endline } \\
\text { and baseline (prevalence, community } \\
\text { acceptance, factors) } \\
\text { - integrate with health extension program } \\
\text { - scale up to other sites } \\
\text { - learn from success and failure }\end{array}$ \\
\hline
\end{tabular}


Phase of intervention and monitoring and evaluation (M\&E)

\begin{tabular}{ll}
\hline Phase 1: Baseline & Phase 2: intervention implementation \\
& \\
-Baseline data collection & -advocacy meeting with local administrative \\
-Instrument validation & bodies and stakeholders to explore \\
-Contextualization of the & implementation barriers and also enhance \\
intervention & engagement of stakeholders \\
-explore community & -community mobilization \\
perceptions & -awareness creation to the women on \\
& gender equality, rights and community norm \\
& -awareness creation and enhance \\
& husband/partner involvement \\
& -Training of community representatives to \\
& involve them in the traditional norm \\
& change agent \\
& -traditional coffee ceremonies and \\
& community conversation
\end{tabular}

\author{
Phase 4: dissemination \\ and scale up \\ *Dissemination \\ -Advocacy meeting \\ -policy Brief \\ -publication in peer \\ review journals \\ -local Media \\ -use social media \\ -present in \\ conference s \\ *Scale up of \\ successful experiences \\ -learn from barriers \\ and propose alternative \\ solutions \\ -integrate with health \\ extension program \\ -engaging stakeholders/ \\ community
}

\section{$M \& E$}

-measurement tool and intervention material validation -number of women interviewed per day and completeness and consistency of questionnaire

\section{$M \& E$}

-number of advocacy workshop -pre-posttest of the participant -feedback from participants -number of women involve in awareness creation

-number of community representatives trained and involve on community mobilization

-number of husbands/involved and attend awareness creation program

- implementers briefing and debriefing regular session

- KII and FGD on the progress of the intervention and acceptability of the intervention by the community

\section{Discussion}

This study will pilot the feasibility and effectiveness of the community based intervention to prevent domestic VAW in the northwestern Ethiopia. Interventional studies conducted in Uganda indicated that community-based intervention successfully avert VAW and reduced unnecessary spending on related costs [72, 73], On the other hand, a study done in South Africa revealed that integrated alcohol and HIV prevention intervention reduced VAW by $70 \%$, and also the gender based violence with HIV prevention intervention had reduced significantly the intention of perpetration by $50 \%$ [74]. Another study in Ethiopia showed that combined intervention (community engagement with group education) reduced IPV by $60 \%$ [75]. Furthermore, microfinance based intervention brought significant change in three African countries. A study done in Uganda shows that microenterprise as economic empowerment to prevent IPV brought significant improvement on income, women perception on their autonomy, control behaviors and quality of marital relationship [76]. Studies in Côte d'Ivoire (2010-2012) revealed that economic VAW reduced by $61 \%[77,78]$. In addition, financial support to promote safe sex, balance relationship power and transform couple's attitude in Tanzania reduced VAW by $30 \%$. Remarkably, VAW also reduced by $57 \%$ in couples who had equal power [79].

Likewise, a quasi-experimental study employed in Tanzania (2012) confirmed that community based intervention using local mass media and advocacy meeting improve knowledge on sexual VAW significantly from 57.3 to $80.6 \%$. The combined intervention had a substantial effect on awareness raising and improve attitude towards VAW norms $(p<0.001)$ [80]. Therefore, evidence from randomized controlled trail, quasi-experimental and longitudinal studies concluded that community based comprehensive intervention such as integrated IPV prevention 
services (economic empowerment, gender norm transformation to promote gender equality and equitable relationship power, involving men, mass media and advocacy meeting) are some of proven evidences based interventions to prevent IPV. These intervention could tremendously reduce IPV [74-76, 79, 81, 82]. Primary prevention strategies (combined microfinance with addressing gender equality norm or culture transformative training; communication and relationship skills; minimize access to alcohol use, sensitization, health education and other services) are recommended by WHO to prevent VAW [20]. Similarly, the government of Ethiopia has developed a standard operation procedure for responding and prevention sexual VAW, and clearly stated the implementation to the real setting is very limited [49]. Therefore, this piloting feasibility and effectiveness study will address bottlenecks, design community based intervention strategies and mobilize the community effort to tackle domestic VAW.

\section{Plan for dissemination of research findings}

At the end of the interventional study, a study finding will be compiled. The finding will be disseminated to key stakeholders involving in the study. Scale upping and follow up will be made to ensure the sustainability of the intervention to prevent domestic VAW. The principal investigator will take the leading role of the finding dissemination activities. Short communications (poster, policy brief, abstract presentations) will be carried out. Efforts will be made to publish the finding in international peer reviewed and reputed journals.

\section{Abbreviations \\ CEDAW: Convention on Elimination of any Discriminations against Women; CFIR: Consolidated Framework for Implementation Research; Cl: Confidence Interval; DID: Difference in Differences; FGD: Focus Group Discussion; HEW: Health Extension Worker; HIV: Human Immunodeficiency Virus; IPV: Intimate Partner Violence; ITTA: Intention to Treat Analysis; KII: Key informant Interview; M\&E: Monitoring and Evaluation; \\ NGO: Nongovernmental Organization; STI: Sexual Transmitted Infection; TDR: Tropical Disease Research; UNFPA: United Nations population Fund: VAW: Violence against Women; WHO: World Health Organization}

\section{Acknowledgements}

We would like to thank School of Public Health, University of Ghana and TDR/WHO for financial support. We would like to thank Awi zone health department and women and children affair department for their cooperativeness and preliminary information.

\section{Funding}

This study is financially supported by Tropical Disease Research (TDR)/WHO in collaboration with School of Public Health, University of Ghana.

\section{Availability of data and materials}

Not applicable

\section{Authors' contributions}

AS conceived and designed the study. AS, AA, KT, AM and NA have developed the research protocol. AS wrote the protocol manuscript. All authors extensively review the manuscript and incorporate their intellectual inputs in the protocol development. All authors read and approved the final version of the manuscript.

\section{Ethics approval and consent to participate}

Ethical approval is obtained from Institutional Health Research Ethical Review Committee at College of Health and Medical Sciences at Haramaya University (Ref.No.IHRERC/146/2017). The purpose of the study will be explained and informed consent will secured from study participants. All participants' information will be kept confidential anonymously. Alternative questionnaire will provide to data collectors to minimize breach of confidentiality in case of third person comes while interviewing.

\section{Consent for publication}

Not applicable

\section{Competing interests}

The authors declare that have no competing interests.

\section{Publisher's Note}

Springer Nature remains neutral with regard to jurisdictional claims in published maps and institutional affiliations.

Received: 23 October 2017 Accepted: 10 November 2017

Published online: 21 November 2017

\section{References}

1. World Health Organization. Addressing violence against women and achieving the Millennium Development Goals [Internet]. Geneva: World Health Orgnization; 2005. Available from: http://www.who.int/gender/en

2. Population Reference Bureau TIGWG (IGWG). Gender-Based Violence and Reproductive Health \& HIV/AIDS. Summary of technical update. [Internet]. Washington, DC 20009-5728; 2002. Available from: www.prb. org or www.igwg.org

3. USAID, IGWG P. Gender-based violence: impediment to reproductive health; 2010. p. 2.

4. Oxfam. Eending Violence Against Women; An Oxfam Guide. 2012

5. WHO. Violence against women and HIV/AIDS: critical intersections intimate partner violence and HIV / AIDS. WHO bulletin Series. 2004;1:1-9. Available from: genderandhealth@who.int

6. UNIFEM AU. Domestic violence fact sheet. A 2010 Lenten study compiled by the world Council of Churches, the world student Christian Federation and the world YWCA. 2010. Available from: http://women. overcomingviolence.org.

7. World Health Organization. Global and regional estimates of violence against women: prevalence and health effects of intimate partner violence and non-partner sexual violence [Internet]. Geneva: World Health Orgnization; 2013. Available from: www.who.int/reproductivehealth

8. Boldosser-Boesch A, Byrnes D, Carr C, Farid S, Lovell K, Minchew H, Omang J, Russell R, Warner A. Sexual and Reproductive Health and Rights (SRHR) and the Post- Development Agenda. Brief Cards. 2015.

9. Watts C, Zimmerman C. Violence against women I violence against women : global scope and magnitude. Lancet. 2002;359:1232-7.

10. Inge Baumgarten AE. Ending Violence against Women and Girls; Reduction and prevention of gender-based violence as contribution to the protection of human rights and to development. African Division. 2003.

11. Ellsberg M, Jansen HAFM, Heise L, Watts CH, García-moreno C, Study WHOM. Intimate partner violence and women's physical and mental health in the WHO multi-country study on women's health and domestic violence: an observational study. Lancet. 2008;371:1165-72.

12. Jewkes RK, Levin JB, Penn-kekana LA. Gender inequalities, intimate partner violence and HIV preventive practices: findings of a south African crosssectional study. Soc Sci Med. 2003;56:125-34.

13. Koenig MA, Lutalo T, Zhao F, Nalugoda F, Wabwire-mangen F, Kiwanuka N, et al. Domestic violence in rural Uganda: evidence from a community-based study. Bull World Health Organ. 2003;81:53-60.

14. Kouyoumdjian FG, Findlay N, Schwandt M, Calzavara LM. A systematic review of the relationships between intimate partner violence and HIV / AIDS. PLoS One. 2013;8(11):e81044.

15. Jamison DT, Summers LH, Alleyne G, Arrow KJ, Berkley S, Binagwaho A, et al. Global health 2035: a world converging within a generation. Lancet. 2014;382(9908):1898-955. Available from: https://doi.org/10.1016/S01406736(13)62105-4

16. Union A. Mapto Plan of Action 2016-2030 for The Operationalization of The Continental Policy Framework for Sexual and Reproductive Health and 
Rights. In: Universal Access to Comprehensive Sexual and Reproductive Health Services In Africa MAPUTO [Internet]. Addis Ababa: The African Union Commission; 2016. Available from: www.au.int

17. Remme M, Siapka M, Vassall A, Heise L, Jacobi J, Ahumada C, et al. Review article the cost and cost-effectiveness of gender-responsive interventions for HIV : a systematic review. J Int AIDS Soc. 2014;17:19228. Available from: http://www.jiasociety.org/index.php/jias/article/view/19228 | http://dx.doi. org/10.7448/IAS.17.1.19228

18. Das S, Bapat U, More NS, Alcock G, Joshi W, Pantvaidya S, et al. Intimate partner violence against women during and after pregnancy: a crosssectional study in Mumbai slums. BMC Public Health. 2013;13:817. Available from: BMC Public Health

19. Pallitto CC, Campo PO. Community level effects of gender inequality on intimate partner violence and unintended pregnancy in Colombia : testing the feminist perspective. Soc Sci Med. 2005;60:2205-16. Available from: www.elsevier.com/locate/socscimed

20. World Health Organization. Violence Against Women;Intimate Partner Violence and Sexual Violence.

21. Agrawal A, Bloom SS, Suchindran C, Curtis S, Angeles G. Gender-based power and couples' HIV risk in Uttar Pradesh and Uttarakhand, North India. HHS public access. Int Perspect Sex Reprod Health. 2015;40(4):196-205.

22. Laisser RM, Nyström L, Lugina HI, Emmelin M. Community perceptions of intimate partner violence - a qualitative study from urban Tanzania. BMC Womens Health. 2011;11:13. Available from: http:/www.biomedcentral.com/ 1472-6874/11/13

23. Mukanangana F, Moyo S, Zvoushe A, Rusinga O. Gender based violence and its effects on women 's reproductive Health : the case of Hatcliffe, Harare, Zimbabwe. Afr J Reprod Health. 2014;18(1):110-22.

24. Feder $\mathrm{G}$, Howard LM, Trevillion K. Experiences of domestic violence and mental disorders: a systematic review and meta-analysis. PLoS One. 2012;7(12):e51740.

25. Pico-alfonso MA. Psychological intimate partner violence: the major predictor of posttraumatic stress disorder in abused women. Neurosci Biobehav Rev. 2005;29:181-93.

26. Deyessa N, Berhane Y, Alem A, Ellsberg M, Emmelin M, Hogberg U, et al. Clinical practice and epidemiology intimate partner violence and depression among women in rural Ethiopia : a cross-sectional study. Clin Pract Epidemiol Ment Heal. 2009;5:8. Available from: http://www. cpementalhealth.com/content/5/1/8

27. Yigzaw T, Yibrie A, Kebede Y. Domestic violence around Gondar in Northwest Ethiopia. Ethiop J Health Dev. 2004;18(3):133-9.

28. Guruge S, Bender A, Aga F, Hyman I, Tamiru M, Hailemariam D, Kassa A, Refaie-Shirpak K. Towards a global interdisciplinary evidence-informed practice: intimate partner violence in the Ethiopian context. International Scholarly Research Network. ISRN Nursing Volume 2012, Article ID 307271. doi:10.5402/2012/307271

29. Abate BA, Wossen BA, Degfie TT. Determinants of intimate partner violence during pregnancy among married women in Abay Chomen district, western Ethiopia : a community based cross sectional study. BMC Womens Health. 2016;16:16. Available from: https://doi.org/10. 1186/s12905-016-0294-6

30. Dunkle KL, Jewkes RK, Brown HC, Gray GE, Mcintryre JA, Harlow SD. Genderbased violence, relationship power, and risk of HIV infection in women attending antenatal clinics in South Africa. Lancet. 2004;363:1415-21.

31. Shi C, Kouyoumdjian FG, Dushoff J. Intimate partner violence is associated with HIV infection in women in Kenya : a cross-sectional analysis. BMC Public Health. 2013;13:512. Available from: http://www.biomedcentral.com/ $1471-2458 / 13 / 512$

32. Onsomu EO, Abuya BA, Okech IN, Rosen DL, Duren-Winfield V Simmons AC. Association between domestic violence and HIV serostatus among married and formerly married women in Kenya. Heal Care Women Int. 2015;36(2):205-28.

33. Li Y, Marshall CM, Rees HC, Nunez A, Ezeanolue EE, Ehiri JE. Intimate partner violence and HIV infection among women: a systematic review and meta-analysis. J Int AIDS Soc. 2014;17(18845). Available from: http:// www.jiasociety.org/index.php/jias/article/view/18845 | https://doi.org/10. 7448/IAS.17.1.18845

34. Harling G, Msisha W, Subramanian S V. No Association between HIV and Intimate Partner Violence among Women in 10 Developing Countries. 2010;5(12).

35. Decker MR, Seage GR III, Hemenway D, Raj A, Saggurti N, Balaiah D, Silverman JG. Intimate partner violence functions as both a risk marker and risk factor for Women's HIV infection: findings from Indian husband-wife dyads. J Acquir Immune Defic Syndr. 2009;51(5):593-600.

36. Maman S, et al. Intersection of intimate partner violence and HIV in women. Soc Sci Med. 2000;50(4):459-78. Available from: www.cdc.gov/hiv and www. cdc.gov/violenceprevention

37. Berg-beckhoff G. Intimate partner violence (physical and sexual) and sexually transmitted infection: results from Nepal demographic health survey 2011. Int J Women's Heal. 2014;6:75-82. Available from: https://doi. org/10.2147/JWH.S54609

38. Sigbeku OA, Fawole Ol, Ogunniyan TB, Statistics M. Experiece of intimate partner violence as a predictor of sexually transmitted infections among married women Nigeria. Ann Ibd Pg Med. 2015;13(1):6-16.

39. Pallitto CC, O'Campo P. And unintended pregnancy: analysis of a National Sample from Colombia. Int Fam Plan Perspect. 2004;30(4):165-73.

40. Rahman M. Intimate partner violence and termination of pregnancy: a cross-sectional study of married Bangladeshi women. Reprod Health. 2015; 12:102. Available from: https://doi.org/10.1186/s12978-015-0095-7

41. Nguyen PH, Van Nguyen S, Quang M, Nguyen NT, Keithly SC, Mai LT, et al. The association and a potential pathway between gender-based violence and induced abortion in Thai Nguyen province, Vietnam. Glob Health Action. 2012;5:19006. 11. Available from: https://doi.org/10.3402/ gha.v5i0.19006

42. Antai D, Adaji S. Community-level influences on women's experience of intimate partner violence and terminated pregnancy in Nigeria: a multilevel analysis. BMC Pregnancy Childbirth. 2012;12:128. Available from: BMC Pregnancy and Childbirth

43. Rahman M, Nakamura K, Seino K, Kizuki M. Intimate partner violence and use of reproductive health services among married women : evidence from a national Bangladeshi sample. BMC Public Health. 2012;12:913. Available from: http://www.biomedcentral.com/1471-2458/12/913

44. Muralidharan, A., J. Fehringer, S. Pappa, E. Rottach, M. Das and M. Mandal. Transforming Gender Norms, Roles, and Power Dynmaics for Evidence from a Health Programs in Low and Middle Income Countries. Washington DC; 2015.

45. Semahegn A, Mengistie B. Domestic violence against women and associated factors in Ethiopia; systematic review. Reprod Health. 2015;12:78. Available from: https://doi.org/10.1186/s12978-015-0072-1

46. FDRE. Constitution of The Federal Democratic Republic of Ethiopia Constitution of The Federal Democratic Republic of Ethiopia. Addis Ababa Ethiopia; 1994.

47. FDRE. The criminal code of the Federal Democratic Republic of Ethiopia 2004. Proclamation no.414/2004. Addis Ababa, Ethiopia: Federal Democratic Republic of Ethiopia; 2005.

48. FDRE. The Revised Family Code Procalmation No.213/2000. Addis Ababa, Ethiopia; 2000. p. 96

49. FMOH. Standard Operation procedure for the response and prevention of sexual violence in Ethiopia: Federal Democratic Republic of Ethiopia Minstry of Health. Addis Ababa: Ministry of Health; 2016.

50. Semahegn A, Belachew T, Abdulahi M. Domestic violence and its predictors among married women in reproductive age in Fagitalekoma Woreda, Awi zone, Amhara regional state, north western Ethiopia. Reprod Health. 2013;10:63. Available from: http://www.reproductivehealth-journal.com/content/10/1/63

51. Zhong B. How to calculate sample size in randomized controlled Trial ? J Thorac Dis. 2009;1 (1):51-4.

52. Abramsky T, Devries K, Kiss L, Nakuti J, Kyegombe N, Starmann E, et al. Findings from the SASA! Study: a cluster randomized controlled trial to assess the impact of a community mobilization intervention to prevent violence against women and reduce HIV risk in Kampala, Uganda. MBC Med. 2014;12:122. Available from: http://www.biomedcentral.com/1741$7015 / 12 / 122$

53. Central Statistical Agency (CSA). [Ethiopia] and ICF. 2016. Ethiopia Demographic and Health Survey 2016. Addis Ababa, Ethiopia, and Rockville, Maryland, USA: CSA and ICF. Addis Ababa, Ethiopia; 2016.

54. Rahman M, Nakamura K, Seino K, Kizuki M. Does gender inequity increase the risk of intimate partner violence among Women ? Evidence from a National Bangladeshi Sample. PLoS One. 2013;8(12):e82423.

55. Sapkota D, Bhattarai S, Baral D, Pokharel PK. Domestic violence and its associated factors among married women of a village development committee of rural Nepal. BMC Res Notes. 2016:9:178. Available from: "https://doi.org/10.1186/s13104-016-1986-6 
56. Lamichhane P, Puri M, Tamang J, Dulal B. Women's status and violence against young married women in rural Nepal. BMC Womens Health. 2011; 11:19. Available from: http://www.biomedcentral.com/1472-6874/11/19

57. Dalal K, Wang S, Svanström L. Intimate partner violence against women in Nepal: an analysis through in- dividual, empowerment, family and societal level factors. J Res Heal Sci J. 2014;14(4):251-7.

58. Uthman OA, Moradi T, Lawoko S. Are individual and community acceptance and witnessing of intimate partner violence related to its Occurrence? Multilevel Structural Equation Model. PLoS One 2011;6(12):e27738.

59. Shannon K, Leiter K, Phaladze N, Hlanze Z, Tsai AC, lacopino V, et al Gender inequity norms are associated with increased male-perpetrated rape and sexual risks for HIV infection in Botswana and Swaziland. PLoS One. 2012;7(1):e28739.

60. Abramsky T, Watts CH, Garcia-moreno C, Devries K, Kiss L, Ellsberg M, et al. What factors are associated with recent intimate partner violence? Findings from the WHO multi-country study on women's health and domestic violence. BMC Public Health. 2011;11:109. Available from: http://www. biomedcentral.com/1471-2458/11/109

61. Ismayilova L. Spousal violence in 5 transitional Countries : a populationbased multilevel analysis of individual and contextual factors. Am J Public Heal. 2015;105:e12-22.

62. Hayati EN, Högberg U, Hakimi M, Ellsberg MC, Emmelin M. Behind the silence of harmony: risk factors for physical and sexual violence among women in rural Indonesia. BMC Womens Health. 2011;11:52. Available from: http://www.biomedcentral.com/1472-6874/11/52

63. Antai $\mathrm{D}$. Traumatic physical health consequences of intimate partner violence against women: what is the role of community-level factors? BMC Womens Health. 2011;11:56. Available from: http://www.biomedcentral.com/ 1472-6874/11/56

64. Uthman OA, Lawoko S, Moradi T. Factors associated with attitudes towards intimate partner violence against women : a comparative analysis of 17 sub-Saharan countries. BMC Int Health Hum Rights. 2009;9:14. Available from: http://www.biomedcentral.com/1472-698X/9/14

65. Conroy AA. Gender, power, and intimate partner violence: a study on couples from rural Malawi. J Interpers Violence. 2014;29(5):866-88.

66. Heise L. Violence against women: an integrated, ecological framework Violence Against Women. 1998;4(3):262-90. Available from: http://vaw. sagepub.com/cgi/content/abstract/4/3/262

67. Ellsberg $M$, and Heise L. Researching Violence Against Women: A Practical Guide for Researchers and Activists. Washington DC, United States: World HealthOrganization, PATH; 2005.

68. Central Statistics Agency [Ethiopia]. Ethiopian demographic aand Health survey 2016;Central Statistical Agency Addis Ababa, Ethiopia The DHS Program ICF Rockville, Maryland, USA. [Internet]. Addis Ababa, Ethiopia; 2016. Available from: www.DHSprogram.com

69. Central Statistical Agency [Ethiopia]. Ethiopia Demographic and Health Survey 2005; Central Statistical Agency Addis Ababa, Ethiopia ORC Macro Calverton, Maryland, USA [Internet]. Addis Ababa, Ethiopia; 2006. Available from: http://www.measuredhs.com.

70. Central Statistical Agency [Ethiopia]. Ethiopia Demographic and Health Survey 2011; Central Statistical Agency Addis Ababa, Ethiopia; ICF International Calverton, Maryland, USA. [Internet]. Addis Ababa, Ethiopia; 2012. Available from: http://www.measuredhs.com

71. Azmat SK, Hameed W, Hamza HB, Mustafa G, Ishaque M, Abbas G, et al. Engaging with community-based public and private mid-level providers for promoting the use of modern contraceptive methods in rural Pakistan : results from two innovative birth spacing interventions. Reprod Health. 2016;13:25. Available from: https://doi.org/10.1186/s12978-016-0145-9

72. Michaels-igbokwe C, Abramsky T, Devries K, Michau L, Musuya T, Watts C. Cost and cost-effectiveness analysis of a community mobilisation intervention to reduce intimate partner violence in. BMC Public Health [Internet]. 2016;16:196. Available from: https://doi.org/10.1186/s12889-0162883-6

73. Wagman JA, Gray RH, Campbell JC, Thoma M, Ssekasanvu J, Nalugoda F, et al. Effectiveness of an integrated intimate partner violence and HIV prevention intervention in Rakai, Uganda: analysis of an intervention in an existing cluster randomised cohort. Lancet Glob Heal. 2015;3(1):e23-33.

74. Kalichman SC, Simbayi LC, Cloete A, Clayford M, Mxoli M, Smith G, et al. Integrated gender-based violence and HIV risk reduction intervention for south African men: results of a quasi-experimental field trial. Prev Sci. 2011;10(3):260-9.
75. Pulerwitz J, Hughes L, Mehta M, Kidanu A, Verani F, Tewolde S. Changing gender norms and reducing intimate partner violence: results from a quasiexperimental intervention study with young men in Ethiopia. Am J Public Heal. 2015;105:132-7.

76. Green EP, Blattman C, Jamison J, Annan J. Social Science \& Medicine Women's entrepreneurship and intimate partner violence: a cluster randomized trial of microenterprise assistance and partner participation in post-con fl ict Uganda. Soc Sci Med. 2015;133:177-88. Available from: https://doi.org/10.1016/j.socscimed.2015.03.042

77. Gupta J, Falb KL, Lehmann H, Kpebo D, Xuan Z, Hossain M, et al. Gender norms and economic empowerment intervention to reduce intimate partner violence against women in rural Côte d' Ivoire : a randomized controlled pilot study. BMC Int Health Hum Rights. 2013;13:46. Available from: http://www.biomedcentral.com/1472-698X/13/46

78. Falb KL, Annan J, Kpebo D, et al. Differential impacts of an intimate partner violence prevention program based on child marriage status in rural Côte d'Ivoire. J Adolesc Health. 2015;57(5):553-8. Available from: https://doi.org/ 10.1016/j.jadohealth.2015.08.001

79. Krishnan S, Vohra D, De Walque D, Medlin C, Nathan R, Dow WH. Tanzanian couples ' perspectives on gender equity, relationship power, and intimate partner violence: findings from the RESPECT study. AIDS Res Treat. 2012; 2012:Article ID 187890.

80. Abeid M, Muganyizi P, Mpembeni R, Darj E, Axemo P. A communitybased intervention for improving health- seeking behavior among sexual violence survivors: a controlled before and after design study in rural Tanzania. Glob Health Action. 2015:8(28608):9. Available from: https://doi.org/10.3402/gha.v8.28608

81. Kim JC, Watts $\mathrm{CH}$, Hargreaves JR, Ndhlovu LX, Phetla G, Morison LA, et al. Understanding the impact of a microfinance-based intervention on Women's empowerment and the reduction of intimate partner violence in South Africa. Am J Public Heal. 2007:97(10):1794-802.

82. Jewkes RK, Dunkle K, Nduna M, Shai N. Intimate partner violence, relationship power inequity, and incidence of HIV infection in young women in South Africa: a cohort study. Lancet. 2010;376:41-8. Available from: https://doi.org/10.1016/S0140-6736(10)60548-X

\section{Submit your next manuscript to BioMed Central and we will help you at every step:}

- We accept pre-submission inquiries

- Our selector tool helps you to find the most relevant journal

- We provide round the clock customer support

- Convenient online submission

- Thorough peer review

- Inclusion in PubMed and all major indexing services

- Maximum visibility for your research

Submit your manuscript at www.biomedcentral.com/submit
Biomed Central 